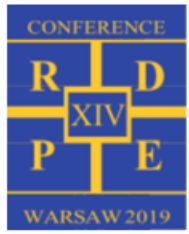

\title{
Analysis and management of operating risk created by turbine operation under flexible regimes
}

\author{
Andrzej Rusin ${ }^{1,}{ }^{*}$, Adam Wojaczek ${ }^{2}$, and Martyna Tomala ${ }^{3}$ \\ 1,2,3 Silesian University of Technology - Institute of Power Engineering and Turbomachinery, Konarskiego 18, 44-100 Gliwice, \\ Andrzej.Rusin@polsl.pl, A dam.Wojaczek@polsl.pl, M artyna.Tomala@polsl.pl,
}

\begin{abstract}
The new conditions in which coal-fired power plants, especially $200 \mathrm{M} \mathrm{W}$ units, have to operate require a considerable increase in the dynamics of their operation. The power unit start-up frequency increases and so does the frequency of changes in loads. This intensifies some wear processes, such as lowcycle fatigue and crack propagation in particular. Therefore, further operation of power units which have al ready been in service for a long time has to be supplemented with results of analyses and tests taking account of the intensification of wear processes. The paper presents a proposal for an extension of standard diagnostic testing of turbines by adding small punch tests (SPT) of the rotor material micro specimens. The SPT method enables a fast quasi non-destructive assessment of changes in mechanical properties, especially rotor steel embrittlement due to the turbine previous operation. The other element of the proposed testing is the analysis of the propagation rate of potential cracks in the rotor and assessment of the rotor failure probability for different scenarios of the power unit further operation.
\end{abstract}

\section{Introduction}

The new conditions in which coal-fired power plants, especially $200 \mathrm{MW}$ units, have to operate require a considerable increase in the dynamics of their operation. Considering the priority of energy generation from renewable sources, more and more often now conventional power plants have to play the role of sources balancing the demand for electricity in the power system. This in turn necessitates a change in the operation of individual power units from constant-load operation to cyclical operation characterized by frequent shutdowns and start-ups, as well as variable loads $[1,2]$. A nother operating issue is that a large proportion of the power units have al ready been in service for longer than their design service life and, despite many upgrades, their further operation requires special supervision. The age structure of Polish power plants presented in Fig. 1 indicates that even though state-of-the-art low-emission supercritical power units have been gradually replacing the $200 \mathrm{MW}$ and $400 \mathrm{MW}$ power units with a long design service life, the "old" power plants will remain dominant in the power system and they will be operated for another several years.

On the other hand, ensuring appropriate reliability of energy supplies requires high availability of energy sources, including coal-fired power units. And this requires actions preventing a serious failure. This is where diagnostic testing has a crucial role to play. Its basic aim is to detect symptoms pointing to the degree of wear of the element under consideration. The wide variety of wear processes involving degradation of the elements of power machinery and equipment results in a similar variety of wear symptoms. A common symptom of the material increasing degradation is the appearance of micro and then macro cracks. In the case of turbine rotors, the cracks further propagation and reaching critical dimensions will potentially create the most dangerous scenario of a failure. Diagnostic testing must therefore enable identification of the location and size of potential cracks on the one hand, and assessment of ageing-related changes in mechanical properties of turbine steel on the other.

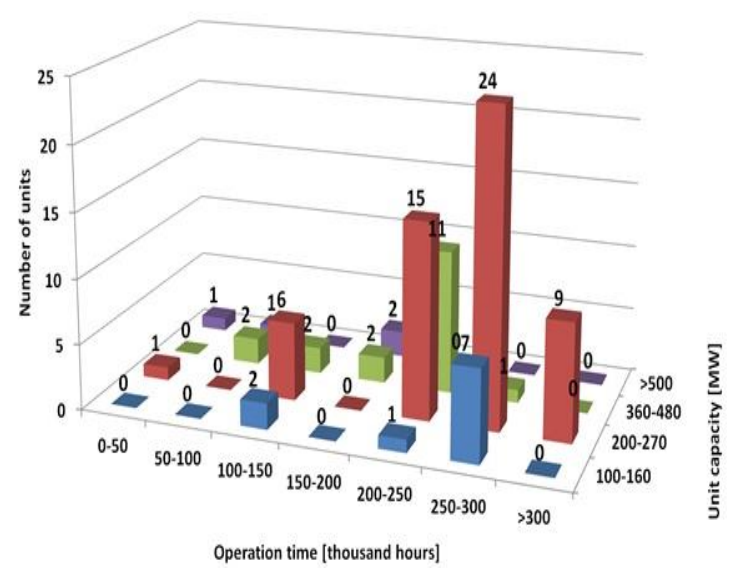

Fig. 1. A ge structure of coal-fired power units in the power system in Poland

The paper presents an analysis of the risk created by propagation of potential cracks in turbine rotors due to variable operating conditions. Small punch testing (SPT) of the rotor material micro specimens is proposed as the method enabling a fast quasi non-destructive assessment of changes in mechanical properties, including first and foremost rotor steel embrittlement due to the turbine previous operation. M ethods are discussed of estimation of the propagation rate of potential cracks in the rotor and calculation of the rotor failure probability for different scenarios of the power unit further operation. 


\section{Assessment of the risk related to long-term operation of turbine rotors}

\subsection{Crack propagation in the rotor}

A s al ready mentioned, one of the most dangerous scenarios of a turbine failure is an uncontrolled increase in defects being the consequence of technological processes or cracks arising due to material ageing. For this reason, the analysis of the development of potential discontinuities in the rotor has become an important element of life assessment and prediction of the time of further safe operation. How the cracks behave in the material depends on a number of factors, including for example the crack location and the material stress state [3]. Crack propagation under variable loads will be related to fatigue processes, whereas under constant loads - it is the creep process that matters. For a cracked el ement subjected to fatigue and creep processes, the crack propagation rate can be correlated to the stress intensity coefficient $\mathrm{K}$ I defined as:

where:

$$
K_{I}=M \sigma \sqrt{a}
$$

$M$ - non-dimensional function of geometrical parameters of the crack and the element,

$\sigma-$ tensile stress acting on the crack,

$a$ - crack dimension.

Crack propagation under variable loads is described by the following Paris-Erdogon equation [4]:

$$
\frac{d a}{d N}=C(\Delta K)^{m}
$$

where:

$C$ and $m$ - material constants

$\Delta K=K_{\text {Imax }}-K_{\text {Imin }}$

$N$ - number of fatigue cycles.

Crack propagation in a material under creep conditions can be described using the following general relation [4]:

$$
\frac{d a}{d t}=A K^{n}
$$

where:

$A$ and $n$ - material constants,

$t$ - steady-state operation time.

In real operating conditions turbine elements are subjected to both variable loads during transient operation and constant loads during operation with a constant power output. For this reason, both the above-mentioned relations should be used in the assessment of potential crack propagation.

The crack grows steadily until stress intensity coefficient $K$ reaches the limit value of fracture toughness $K_{I C}$, which means that the crack has reached the critical dimension at a given level of tensile stresses acting on the crack surfaces. Therefore, an important element in the assessment of potential threats related to the occurrence of cracks in rotors is the assessment of the stress level in the area where defects and cracks may develop. A nother necessary element of the safety analysis is the assessment of changes in rotor steel properties due to previous operation, including in particular the assessment of the change in fracture toughness.

\subsection{Using small punch testing (SPT) of the rotor material micro specimens for the assessment of changes in mechanical properties}

The material actual mechanical properties, including increased embrittlement of a rotor operated for a long time, can be identified and assessed by performing small punch tests of micro specimens of rotor steel (the SPT method).

The SPT method is the material punch test reduced to a micro scale. It consists in punching a small specimen using a hemispherical indenter. The SPT method enables determination of the material basic mechanical properties, otherwise specified typically by means of static tensile tests and impact strength testing, such as the yield point, tensile strength, brittle-to-ductile transition temperature and the material fracture toughness [5-11]. The SPT specimen is sampled from the rotor using a special device shown in Fig. 2. A specimen sampled from a $200 \mathrm{M} \mathrm{W}$ turbine rotor and the micro specimens in the form of discs with the diameter of 8 $\mathrm{mm}$ and thickness of $0.5 \mathrm{~mm}$ are shown in Fig. 3.

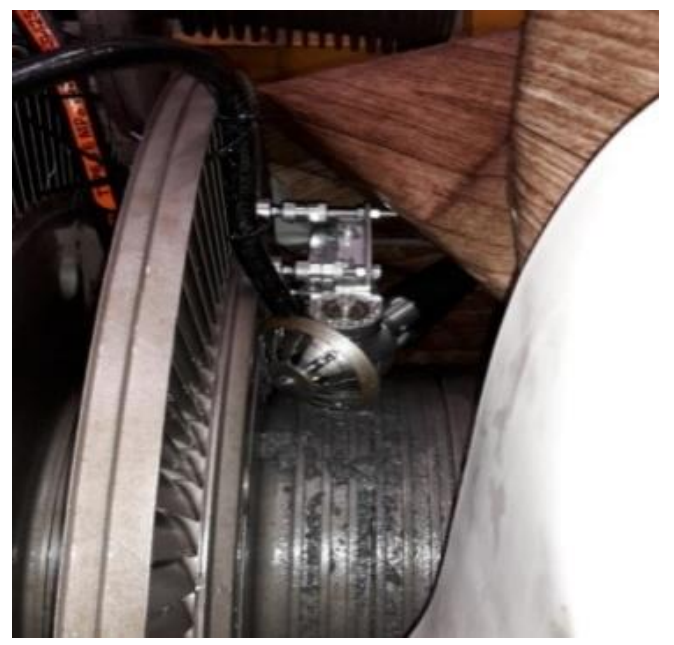

Fig. 2. Specimen sampling from a $200 \mathrm{M} \mathrm{W}$ turbine rotor disc

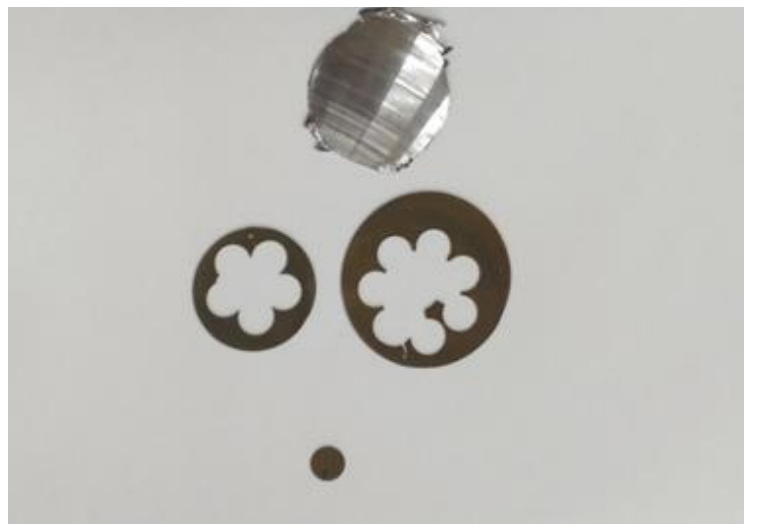

Fig. 3. Rotor material specimen and the micro specimens made of it

The specimens sampled from the rotor inlet and outlet part are then tested by means of the SPT method in ambient temperature and in reduced temperatures. The results of the testing of the properties of the rotor outlet part, which is not loaded thermally, are considered as close to rotor steel initial properties. Example curves illustrating SPT results obtained in ambient temperature for micro specimens sampled from the HP rotor inlet and outlet are shown in Fig. 4. 


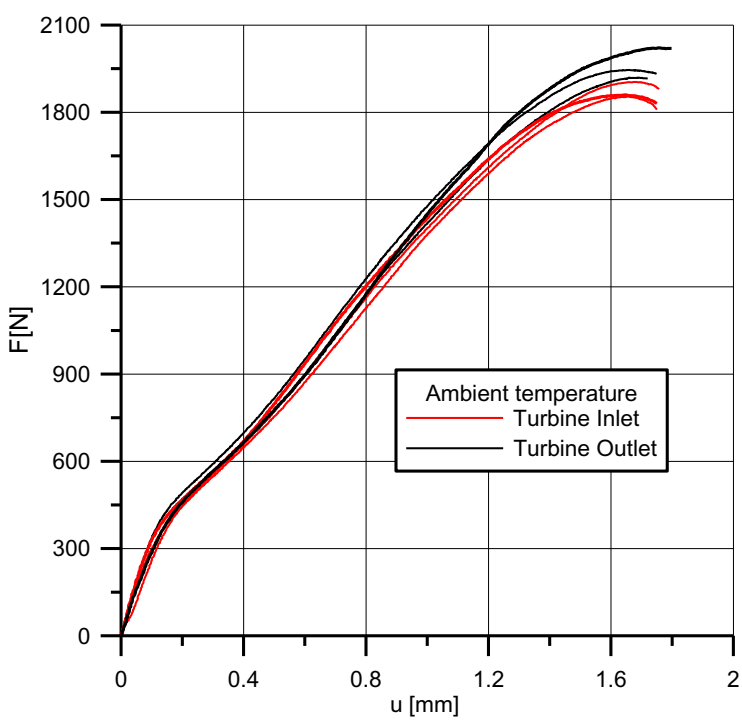

Fig. 4. Testing in ambient temperature - inlet and outlet part specimens

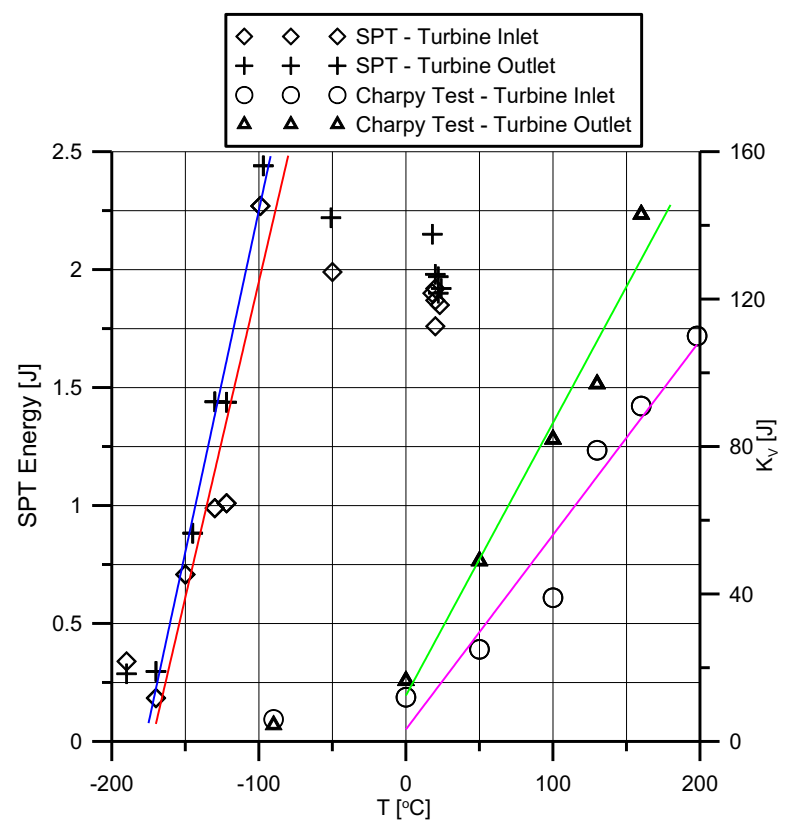

Fig. 5. Comparison of the work of breaking and punching of specimens sampled from the rotor cold and hot end

The testing of micro specimens from the rotor inlet and outlet part makes it also possible to calculate the work of the specimen punching in different temperatures. Using correlations that relate the micro specimen punching work determined in this way to the work of the specimen breaking in a typical impact strength test, it is possible to evaluate temperatures of the FATT brittle-to-ductile transition. By conducting such tests of specimens sampled from the rotor inlet and outlet part, it is possible to assess the decrease in rotor steel fracture toughness due to previous operating conditions. First and foremost, such information decides whether the rotor qualifies for further operation. It al so enables prediction of how much longer the element can be operated safely.

\section{Analysis of the risk of the turbine rotor failure}

\subsection{Stress states in the rotor}

According to the remarks made above, the development of potential defects and cracks in the rotor depends, among others, on the stress state in the crack vicinity. The crack propagation rate will depend, among others, on the value of the stress tensile components. For this reason, the stress-state analysis in all phases of operation becomes an indispensable element of the assessment of the safety of the rotor operation. The maximum stresses arising in transient states of operation, i.e. during start-ups and shutdowns, will determine the amplitude of stresses occurring in a working cycle. And this very amplitude has an impact on the size of the crack increment during the cycle. An example distribution of the circumferential component of stresses in the HP rotor during the heating process is shown in Fig. 6.

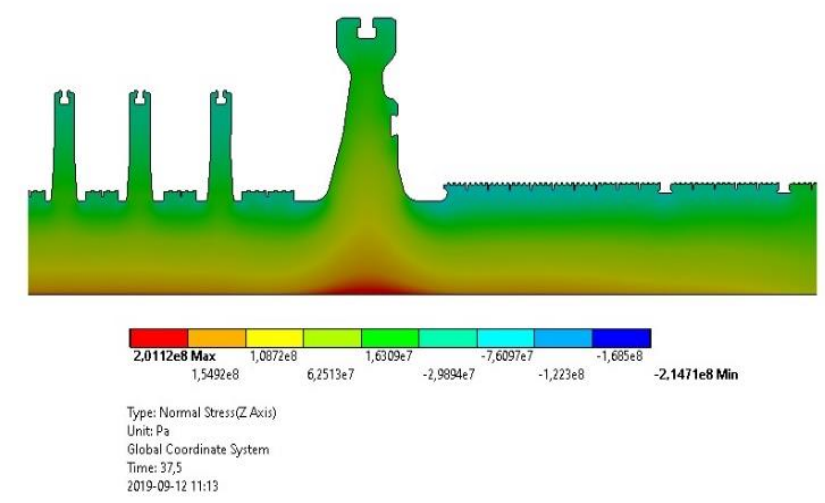

Fig. 6. Distribution of circumferential component of stress in the heating rotor

Fig. 7 presents the distribution of equivalent (von Mises) stresses in the rotor during steady-state operation, when creeprelated stress relaxation occurs. So-calculated stress values are used in further analyses of crack propagation in the rotor.

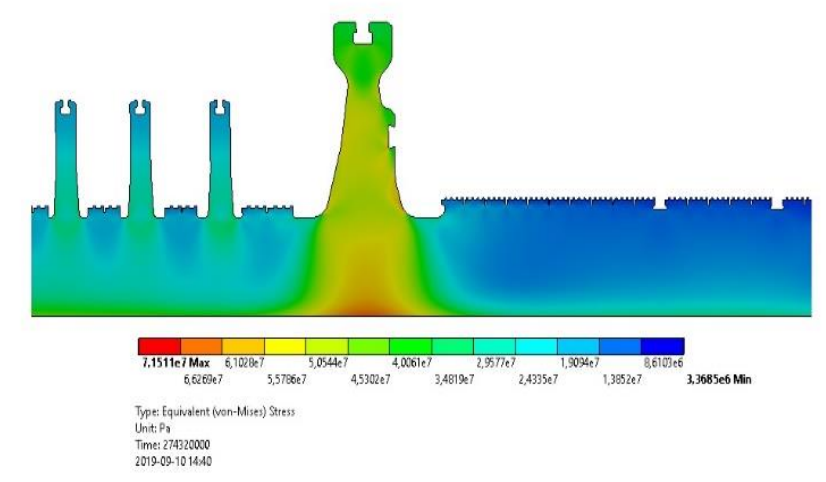

Fig. 7. Equivalent (von $M$ ises) stress distribution in the rotor during creep relaxation process

\subsection{Probability of the rotor failure}

A mong others, the risk analysis procedure includes:

- definition of potential scenarios causing the el ement failure,

- estimation of the probability of the scenarios,

- estimation of the consequences of the el ement failure, 
- assessment of the risk understood as the product of the probability of the element failure and the failure consequences.

$M$ any different scenarios which can cause a failure are taken into account in the analysis of risk related to the power unit operation. In the case of turbines, considering the new, flexible conditions of their operation, the scenarios must take account of processes related to fatigue wear and creep wear, as well as to intensification of other factors, such as erosion and corrosion. When it comes to turbine rotors, the highest risk is related to the scenario of the rotor failure due to crack propagation and the crack reaching critical dimensions.

For this particular scenario, the rotor failure criterion can be written as:

$$
g=a_{c r}-a
$$

where $\boldsymbol{a}_{\boldsymbol{c}}$ is assumed as the crack critical dimension, which results in the rotor immediate destruction. It is calculated from the following relation:

$$
a_{c r}=\left(K_{I C} / M \sigma\right)^{2}
$$

Due to the random character of the quantities in the above formula, i.e. fracture toughness $K_{I} c$ and the maximum tensile stresses acting on the crack surface $\sigma$, the crack critical dimension should also be considered as random. The nature of the crack current dimension a in formula (4) calculated using relations (1) and (2) is also random, and the quantity depends e.g. on the number and type of working cycles, i.e. on the number of start-ups from different thermal states and the level of stresses occurring in subsequent working cycles.

Using these assumptions, the formula defining the probability of the rotor failure can be written as:

$$
P_{f}=P(g \leq 0)
$$

Determination of the probability requires calculations of all the quantities used in formula (4) and formula (5). Example results of calculations of the propagation of a crack located in the HP rotor central hole are shown in Fig. 8 and Fig. 9. The calculations are performed assuming the rotor service life of 20 years, with an average of 6 thousand hours of operation per year. Each year the turbine is started 200 times on average, from three different thermal states. Each of those three types of start-ups involves the occurrence of stresses in the rotor central hole with average stress values of $200 \mathrm{M} \mathrm{Pa}, 250 \mathrm{M} \mathrm{Pa}$ and 300 $\mathrm{MPa}$, respectively. The results shown in the figure bel ow relate to the service life of 20 years assuming operating scenario \#1, according to which each year there are 50 start-ups producing stresses of $200 \mathrm{M} \mathrm{Pa}, 100$ start-ups causing stresses of $250 \mathrm{M} \mathrm{Pa}$ and 50 start-ups resulting in $300 \mathrm{M} \mathrm{Pa}$ stresses. Fig. 9 illustrates the crack propagation calculation results obtained assuming operating scenario \#2, according to which there are 200 startups a year producing average stresses of $200 \mathrm{M} \mathrm{Pa}$. Depending on the size of the initial defect or crack, the crack propagation rate and the crack dimensions can take different values. Therefore, in each specific case the crack initial value should be taken as the value obtained from measurements or the value corresponding to the sensitivity of the instruments used in the detection of defects and cracks.

In the next stage of the analysis, the rotor failure probability is calculated according to relation (6). The mean values and standard deviations of input data treated as random quantities and used in the calculations are listed in Table 1.

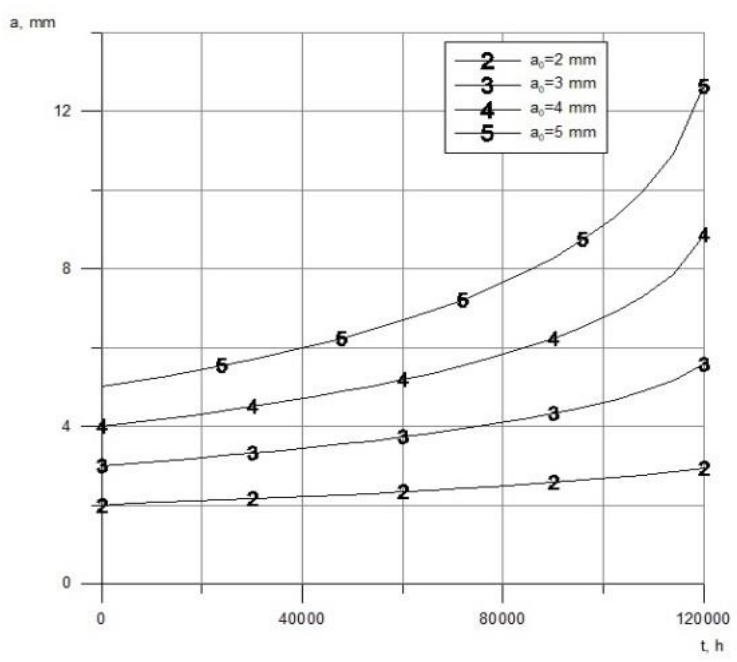

Fig. 8. Crack propagation in the rotor central hole for the crack different initial dimensions - operating scenario \#1

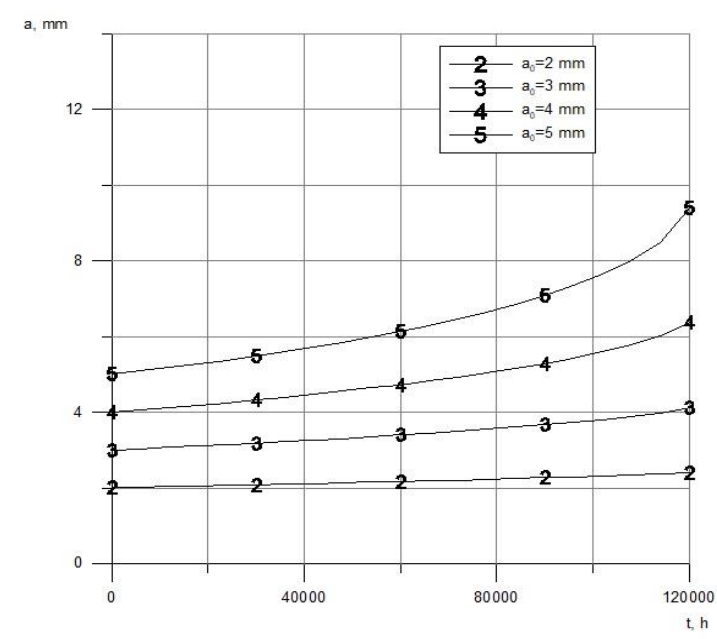

Fig. 9. Crack propagation in the rotor central hole for the crack different initial dimensions - operating scenario \#2

Table 1. M ean values and standard deviation of input data

\begin{tabular}{|c|c|c|}
\hline Input data & Mean value & Standard deviation \\
\hline$\Delta \sigma_{1}$ & $200 \mathrm{M} \mathrm{Pa}$ & $10 \mathrm{M} \mathrm{Pa}$ \\
\hline$\Delta \sigma_{2}$ & $250 \mathrm{M} \mathrm{Pa}$ & $12,5 \mathrm{M} \mathrm{Pa}$ \\
\hline$\Delta \sigma_{3}$ & $300 \mathrm{M} \mathrm{Pa}$ & $15 \mathrm{M} \mathrm{Pa}$ \\
\hline$C$ & $2 \mathrm{e}-12$ & $1 \mathrm{e}-13$ \\
\hline$m$ & 3,4537 & 0,173 \\
\hline$\sigma_{\text {creep }}$ & $65 \mathrm{M} \mathrm{Pa}$ & $3,25 \mathrm{M} \mathrm{Pa}$ \\
\hline$A$ & $3 \mathrm{e}-14$ & $1,5 \mathrm{e}-15$ \\
\hline$n$ & 5,6572 & 0,283 \\
\hline$M$ & 1,98 & 0,086 \\
\hline$a_{0}$ & $2-5 \mathrm{~mm}$ & $0,5 \mathrm{~mm}$ \\
\hline$K_{I c 0}$ & $100 \mathrm{M} \mathrm{Pa} \sqrt{\mathrm{m}}$ & $5 \mathrm{MPa} \sqrt{\mathrm{m}}$ \\
\hline
\end{tabular}

The change in the mean value and standard deviation of the crack dimensions during operation is calculated using the $M$ onte Carlo method [3]. The probability expressed by means of relation (6) is calculated using the FOSM methods [3]. The results of the rotor failure probability calculations for scenario $\# 1$ and scenario \#2 are presented in Fig. 10 and 11. 


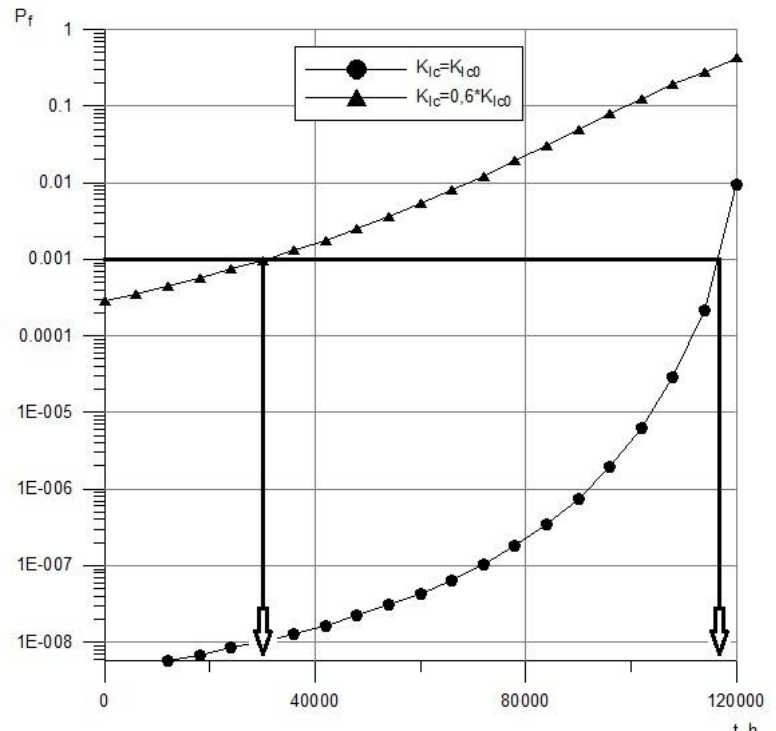

Fig. 10. Probability of the turbine rotor failure for $a_{0}=4 \mathrm{~mm}$ (scenario \#1)

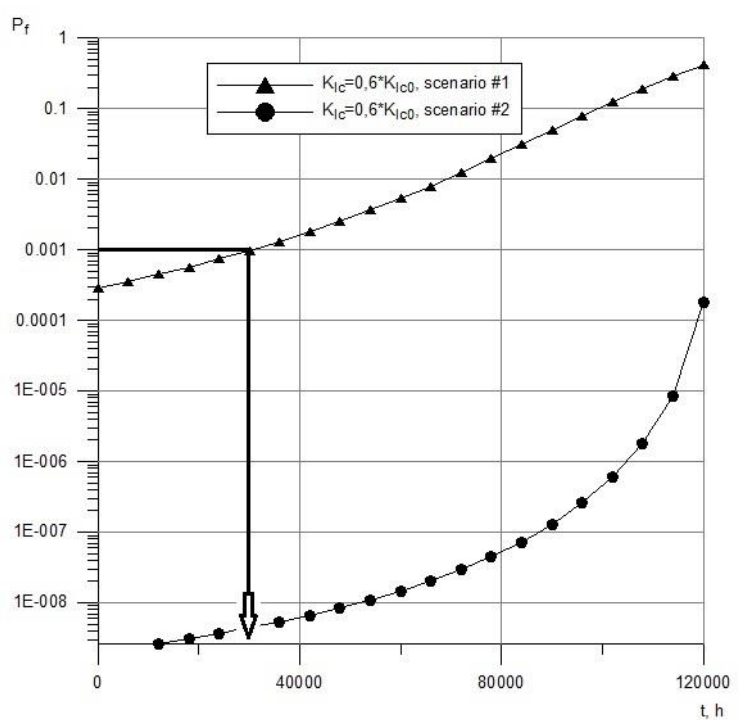

Fig. 11. Probability of the turbine rotor failure for $\mathrm{a}_{0}=4 \mathrm{~mm}$ (scenario \#1 and scenario \#2) for reduced crack resistance $K_{I c}=0,6 \cdot K_{I c 0}$

A ssuming a value of 0.001 as the permissible probability of rotor failure, we can estimate based on the graphs shown in Figure 10 that for a material with unchanged fracture toughness, such a probability will be achieved after approx. $117000 \mathrm{~h}$ of operation. For rotor steel with reduced fracture toughness, such damage probability will occur after approx. $30000 \mathrm{~h}$ of operation. A nalysis of the graphs shown in Figure 11 shows that when operating the turbine according to scenario 2 , this limit probability will not be achieved at all.

\section{Summary and conclusion}

The presented method of analysing the risk related to further operation of turbines which have already been in service for a long time makes use of both materials testing and computer simulations. The result is an estimation of the turbine rotor failure probability for different operating scenarios.
The probability calculated in this way will be a quantity rising over time. As soon as it reaches values assumed as critical, actions have to be taken to reduce the probability and, thereby, lessen the risk related to further operation [12]. In order to protect the rotor from failure, preventive diagnostic testing should be carried out to confirm the crack real dimensions and enable a rational decision whether to continue the turbine operation or replace some of the turbine elements.

\section{References}

1. Rusin, A., Wojaczek, A., Trends of changes in the power generation system structure and their impact on the system reliability, Energy, V ol. 92, pp. 128-134, (2015).

2. Lukowicz, H., Rusin, A., The impact of the control method of cyclic operation on the power unit efficiency and life, Energy, Vol. 150, pp. 565-574, (2018).

3. Rusin A., Awaryjność, niezawodność i ryzyko techniczne w energetyce cieplnej, Wydawnictwo Politechniki Śląskiej,Gliwice, (2008).

4. British Electricity International, Turbines Generators and A ssociated Plant, Pergamon, (1991).

5. Altstadt E., Houska M., Simonovski I., Bruchhausen M., Holmström S., Lacelle R.: On the estimation of ultimate tensile stress from small punch testing, International

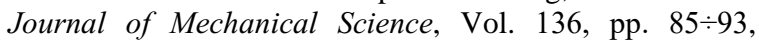
(2018).

6. Altstadt E., Ge H.E., Kuksenko V., Serrano M., Houska M., Lasan M., Bruchhausen M., Lapetite J.M., Dai Y.: Critical evaluation of the small punch test as a screening procedure for mechanical properties, Journal of Nuclear Materials, V ol. 472, pp. 186 $\div 195$, (2016).

7. Ortiz-Mariscal A., Saucedo-M unoz M.L., Naveena, Komazaki S.: A pplication of small punch creep testing for evaluation of creep properties of as-received and artificially aged 5Cr-0,5M o steel, Materials Science and Engineering Vol. A 709, pp. $322 \div 329$, (2018).

8. K umar K., M adhusoodanan K., Singh R.N.: M iniature test techniques for life management of operating equipment, Nuclear Engineering and Design, V ol. 323, pp. $345 \div 358$, (2017).

9. Moreno M.F.: Application of small punch testing on the mechanical and microstructural characterizations of P91 steel at room temperature, International Journal of

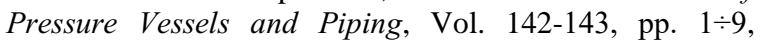
(2016).

10. Rasche S., Kuna M., Improved small punch testing and parameter identification of ductile to brittle materials, International Journal of Pressure Vessels and Piping, $\mathrm{V}$ ol. 125 , pp. $23 \div 34$, (2015).

11. Rodríguez C., Fernández M., Cabezas J.G., Garciá T.E., Belzunce F.J.: The use of the small punch test to solve practical engineering problems, Theoretical and Applied

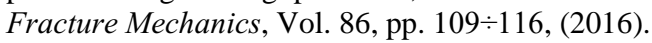

12. Rusin $A$. ., Bieniek $M$.: Maintenance planning of power plant elements based on avoided risk value, Energy, $\mathrm{V}$ ol. 134 , pp. $672 \div 680$, (2017). 